\title{
STUDI KELAYAKAN KAJIAN AKADEMIS PENDIRIAN RUMAH SAKIT IBU DAN ANAK (RSIA) SEMPAJA KOTA SAMARINDA
}

\section{(A FEASIBILITY STUDY OF ACADEMIC STUDY OF MOTHER AND CHILD HOSPITAL ESTABLISHMENT (RSIA) SEMPAJA CITY SAMARINDA)}

\author{
Lamri' $^{1}$, Supriadi $^{1}$, Rahmad Bahtiar $^{2}$, Syahrani $^{2}$, Isnawati $^{3}$ \\ ${ }^{1}$ Politeknik kesehatan Kalimantan Timur \\ Jalan. Wolter Monginsidi No. 38 Samarinda \\ Email: lamri1158@yahoo.com \\ ${ }^{2}$ Universitas Mulawarman Fakultas Kedokteran \\ Jalan. Krayan Kota Samarinda \\ ${ }^{3}$ Fakultas HukumUniversitas 17 Agustus 1945 Samarinda \\ Jalan. Krayan Kota Samarinda
}

Diterima: 13 Agustus 2021; Direvisi: 3 Desember 2021; Disetujui: 30 Desember 2021

\begin{abstract}
The large potential for hospital development in East Kalimantan, especially Samarinda City, can be reflected by the large level of community need for health services. This can be measured by the level of population health through several indicators of mortality, such as the number of maternal deaths, the number of deaths of infants and toddlers, the life span of the newborn, and the number of crude deaths. The potential need for health facilities, one of which is a hospital, can also be seen based on the low comparison of the number of hospital beds compared to the existing population. In the 2015 2020 period alone, the population growth rate of the Samarinda region averaged $1.84 \%$ per year. Because of the very fast population development factor in Samarinda City, this is what demands additional health services. In addition, the rapid development that exists is accompanied by the emergence of environmental pollution due to the impact of the mining business sector and others, demanding the need to improve the quality and quantity of better health services in this region. Therefore, to resolve the issue of equity and improvement of health services, RSIA Sempaja This combination of social and economic services really needs to be developed, considering that RSIA Sempaja is also a facility owned by the Samarinda City government which is legally under the management of the City Health Office. Samarinda.
\end{abstract}

Keywords: Ratio; Government; Health services.

\begin{abstract}
ABSTRAK
Masih besarnya potensi pengembangan rumah sakit di Kalimantan Timur khususnya Kota Samarinda, dapat dicerminkan dengan masih besarnya taraf keperluan masyarakat akan jasa pelayanan kesehatan. Hal ini bisa diukur dengan tingkat kesehatan penduduk melalui beberapa indikator mortalitas misalnya jumlah kematian ibu maternal, jumlah kematian bayi maupun balita, umur hidup bayi lahir, dan jumlah kematian kasar. Potensi kebutuhan fasilitas kesehatan yang salah satunya adalah rumah sakit juga bisa dilihat berdasarkan rendahnya perbandingan jumlah tempat tidur rumah sakit dibandingkan dengan jumlah penduduk yang ada. Pada periode tahun 2015-2020 saja, laju pertumbuhan penduduk wilayah Samarinda rata-rata mencapai $1.84 \%$ pertahun. Oleh karena faktor perkembangan penduduk yang sangat cepat di Kota Samarinda inilah yang menuntut adanya penambahan pelayanan kesehatan. Selain itu, pesatnya pembangunan yang ada disertai dengan timbulnya pencemaran lingkungan akibat dampak sektor bisnis pertambangan dan lain-lain, menuntut perlunya peningkatan kualitas dan kuantitas pelayanan kesehatan yang lebih baik pada wilayah ini. Oleh sebab itu, untuk menyelesaikan perkara pemerataan dan peningkatan pelayanan
\end{abstract}


kesehatan tersebut, RSIA Sempaja Kombinasi antara pelayanan sosial dan ekonomi ini sangat perlu untuk dikembangkan, mengingat RSIA Sempaja ini pun juga merupakan fasilitas milik pemerintah Kota Samarinda yang secara yuridis berada di bawah pengelolaan Dinas Kesehatan Kota Samarinda.

Kata kunci: Rasio; Pemerintah; Pelayanan Kesehatan.

\section{PENDAHULUAN}

Penambahan jumlah penduduk tentunya menambah peluang persaingan dan mengantisipasi pada bisnis serta pemenuhan aneka macam penyediaan sarana dan prasarana serta fasilitas kebutuhan utama masyarakat yang semakin meningkat. Kebutuhan berupa fasilitas kesehatan merupakan satu diantara kebutuhan utama yang dipastikan masih akan sangat layak untuk dibangun mengingat sarana dan prasarana yang terdapat masih kurang memadai, peluang ini terbuka lebar karena untuk mencukupi kebutuhan masyarakat dengan taraf pendapatan ekonomi yang terus bertambah tinggi serta menciptakan pemenuhan akan sarana dan prasarana yang memadai menggunakan tingkat jaminan standar yang diakui baik secara regional maupun nasional.

Dengan adanya Peraturan Menteri Kesehatan Republik Indonesia Nomor 340/MENKES/PER/III/2010 tentang Klasifikasi Rumah Sakit, Rumah Sakit Ibu dan Anak diharapkan memenuhi standar rumah Sakit yang ada. Setiap Rumah Sakit dalam Permenkes tersebut memiliki standar dan batasan terhadap aspek Pelayanan medis, SDM, Perlengkapan, Sarana dan Prasarana serta Administrasi dan Manjemen. Dengan memenuhi persyaratan ini serta pengaturan organisasi yang jelas dan baik, rumah sakit dapat memperoleh banyak kekuatan untuk memastikan kualitas layanan. Dengan memastikan kualitas layanan yang diberikan, rumah sakit telah berhasil menerapkan tata kelola pelayanan yang sangat baik.

Dalam reformasi sistem kesehatan Indonesia, perubahan politik selama 20 tahun terakhir telah melewati Undang-Undang Nomor 22 Tahun 1999 tentang otonomi daerah, dan desentralisasi sedang berlangsung. Hal ini diikuti dengan adanya Undang-Undang Nomor 32 Tahun 2004 tentang Pemerintah Daerah dan Undang-Undang Nomor 33 Tahun 2004 tentang Perimbangan Keuangan antara Pemerintah Pusat dan Daerah. Kedua undang-undang tersebut berdampak besar bagi perkembangan pelayanan kesehatan, khususnya dalam bisnis rumah sakit. Kebijakan pelimpahan wewenang dalam sistem medis merupakan peluang sekaligus ancaman. Sebagai peluang bagi pemerintah daerah untuk memperoleh manfaat dari menjalankan kewenangannya, mereka dapat mengatur bidang kesehatan sesuai dengan keinginan dan kemampuannya. Di sisi lain, penegakan hukum sebagai ancaman tidak lengkap dan tidak konsisten.

Undang-Undang Nomor 40 Tahun 2004 tentang Sistem Jaminan Sosial Nasional dan Undang-Undang Nomor 24 Tahun 2011 tentang Badan Penyelenggaraan Jaminan Sosial juga memberikan peluang bagi Rumah Sakit ibu dan anak. Didukung oleh Peraturan Menteri Kesehatan Republik Indonesia No.001 Tahun 2019 tentang Sistem Rujukan Pelayanan Medis Perorangan, Rumah Sakit Ibu dan Anak merupakan pelayanan selangkah demi selangkah baik pelayanan rawat jalan tingkat pertama maupun pelayanan lanjutan poli baik Poli umum maupun pelayanan rawat jalan, rawat inap dan pelayanan kamar operasi.

Rumah Sakit Ibu dan Anak Sempaja merupakan gabungan dari pelayanan sosial dan pelayanan ekonomi dengan pembangunan dan perluasan fasilitas kesehatan pemerintah. Sebagai bentuk penyelesaian masalah pemerataan dan meningkatkan pelayanan medis, RSIA Sempaja yang merupakan milik Pemerintah Kota Samarinda, secara legal berada di bawah kendali Dinas Kesehatan Kota Samarinda.

Peluang membangun RSIA di Kota Samarinda masih memungkinkan, terlebih lagi jika ditunjang dengan berbagai fasilitas yang modern dan lengkap serta tenaga medis yang handal, maka diharapkan hal ini bisa menjawab kebutuhan warga Kota Samarinda dengan taraf ekonomi menengah keatas, terutama jika rencana pemindahan ibu kota negara (IKN) akan dilaksanakan dalam waktu dekat. 
Klinik Ibu dan Anak terletak di Kecamatan Samarinda Utara, Kelurahan Sempaja Barat, Kota Samarinda. Luas bangunan yang akan digunakan adalah sebesar $3500 \mathrm{~m}^{2}$. Kondisi tempat akan didirikannya RSIA pada saat dilakukan survei adalah tempat yang strategis. Jalan dan system penerangan dalam kondisi baik. Oleh karena itu, ditarik kesimpulan bahwa lokasi tersebut merupakan lokasi yang strategis.

\section{TINJAUAN PUSTAKA}

Tjiptono (1996) mengemukakan ada empat unsur pokok yang terkandung di dalam pelayanan yang prima yaitu: kecepatan, ketepatan, keramahan, dan kenyamanan. Keempat komponen ini merupakan satu kesatuan yang terintegrasi, dalam artian jika ada salah satu komponen yang kurang, maka pelayanan tidak akan excellence, maka semakin layanan yang kita berikan maka konsumen akan merasa puas, hal ini menyebutkan bahwa pelayanan berpengaruh terhadap kepuasan pasien.

Menurut penelitian yang pernah dilakukan yang menyatakan bahwa secara umum, kepuasan pelanggan dikenal sebagai hasil dari kualitas pelayanan, yang artinya memiliki hubungan pada kualitas yang diberi layanan jasa pada konsumen secara positif. Tingkat dari kepuasan pelanggan diyakini searah dengan kualitas layanan jasa yang dirasakan setelah dikonsumsi.

Secara umum studi kelayakan pembangunan RSIA di Kecamatan Sempaja Kota Samarinda, dibuat dengan beberapa proses analisa dan penelitian yang mencakup pengambilan data, analisa data dan pembuatan laporan. Data yang diperoleh mencakup semua data primer dan beberapa data sekunder. Data Primer didapat melalui pengamatan langsung dan wawancara ke beberapa RSIA yang ada di Kota Samarinda Selama jangka waktu proses pembangunan RSIA direncanakan. Data sekunder didapat melalui data yang ada di Dinas Kesehatan dan kantor Badan Pusat Statistik Kota Samarinda serta data tentang perkembangan melalui tingkat regional dan nasional. Proses Pengambilan data dilakukan melalui wawancara, diskusi, observasi dan penelusuran kepustakaan. Dari data yang didapat, selanjutnya dianalisia menggunakan aturan analitis yang berlaku untuk menemukan gambaran kurva kebutuhan layanan medis khususnya rumah sakit ibu dan anak di wilayah Kecamatan Sempaja Kota Samarinda. Kebutuhan pelayanan medis sejalan dengan kebutuhan pelayanan kesehatan yang diberikan oleh Rumah Sakit Ibu dan Anak Sempaja Samarinda. Tata cara penyusunan studi kelayakan ini mengacu pada Pedoman Penyusunan Studi Kelayakan pendirian Rumah Sakit Kementerian Kesehatan Tahun 2012.

Pada penelitian sebelumnya tentang peningkatan status rumah sakit bersalin di Rumah Sakit Ibu dan Anak Putra Dalima, Kota Tangerang Selatan, hasilnya menunjukkan kebutuhan dan permintaan terhadap rumah sakit di kota tersebut terkait dengan kondisi dan masalah kesehatan masyarakat, serta dilihat dari aspek ekonomi, maka peningkatan status rumah sakit Ibu dan Anak Putra Dalima tersebut layak dilaksanakan dan menguntungkan.

Studi kelayakan adalah tentang pengambilan keputusan terhadap layaknya sesuatu untuk dilanjutkan atau ditunda terkait dengan suatu inspirasi usaha atau ide bisnis dengan penekanan pada tujuan yang bisa menjawab pertanyaan penting yaitu, "Apakah perlu melanjutkan ide proyek yang diusulkan?”. Dengan begitu maka dapat diidentifikasi lebih dini bahwa suatu gagasan tidak sesuai dengan harapan guna menghindari penggunan uang, waktu, dan sumber daya yang tidak tepat sasaran. Batasan pembahasan masalah ini dijelaskan sebagai berikut: Identifikasi sasaran yang ingin dicapai meliputi perkiraan permintaan dan penawaran, barang yang ditawarkan, penentuan harga, cara pemasaran, system penjualan, dan analisis SWOT. pengidentifikasian teknis, seperti gambar dan layout produk, penentuan tempat, analisis pemangku kebijakan, struktur organisasi, analisis manajemen pekerjaan dan identifikasi organisasi, termasuk penjelasan pekerjaan, perekrutan pegawai dan seleksi, sistem penggajian dan identifikasi sistem informasi manajemen (termasuk hak paten). Identifikasi masalah ekonomi dan keuangan seperti proyeksi modal kerja, total investasi, dan detail rician yang 
diharapkan. Diakhiri menggunakan usulan/masukan atas output berisi detail perincian tiap-tiap point identifikasi.

Dengan dibangunnya dan beroperasinya Rumah Sakit Ibu dan Anak Sempaja diharapkan dapat memenuhi sasaran pokok yang ingin dicapai yakni sebagai berikut : Peningkatan kemampuan masyarakat Kota Samarinda pada umumnya untuk hidup sehat, Pengurangan jumlah kematian Ibu dan anak, Peningkatan nilai kecukupan gizi masyarakat, Peningkatan kesadaran atas kualitas lingkungan yang sehat, Menjaga tingkat pertumbuhan penduduk melalui program keluarga berencana, dan yang terakhir terlayaninya seluruh peserta jaminan Kesehatan Masyarakat.

\section{METODE}

Identifikasi menggunakan metode SWOT merupakan suatu Identifikasi untuk menganalisis kekuatan dan kelemahan yang ada dalam pelaksanaan pendirian RSIA Sempaja. Kekuatan dan kelemahan yang dapat muncul dari sumber internal disebut kekuatan dan kelemahan. Sedangkan yang mungkin berasal dari luar atau eksternal sering dinamakan sebagai peluang serta ancaman. Berdasarkan analisis lokasi, penggunaan analisis SWOT diperuntukan dalam tahap mengevaluasi faktor-faktor yang mempengaruhi perkembangan properti. Kelebihan harus dioptimalkan, tetapi kelemahan harus dihilangkan agar tidak berdampak buruk.

\section{Identifikasi Internal}

Adalah merupakan Identifikasi terdiri dari Kekuatan serta Peluang merupakan Identifikasi yang bersumber dalam objek itu sendiri. Misalnya objeknya adalah sebuah Struktur organisasi RSIA, maka Identifikasi internalnya meliputi kualitas SDM didalam Rumah Sakit, Kualitas manajemen keuangan di dalam Rumah Sakit dan lain-lain. Dari sini kita sepakati bahwa yang kita bahas adalah identifikasi Struktur Organisasi Rumah Sakit.

Tabel 1.

Internal Identifikasi Analisis Kekuatan (Strength)

\begin{tabular}{|c|c|c|c|c|c|}
\hline No & Identifikasi Kekuatan & Nilai & Bobot & Rating & Skor \\
\hline 1 & RSIA mempunyai tempat Lokasi sangat strategis. & 1 & 0,2 & 4 & 0,8 \\
\hline 2 & $\begin{array}{l}\text { RSIA mempunyai peralatan yang cukup terbaru memadai } \\
\text { ( Seperti : Alat Hematology Matic,Panoramic Dentic) }\end{array}$ & 1 & 0,1 & 3 & 0,3 \\
\hline 3 & RSR RSIA Mempunyai Sistem Informasi yang terkoneksi & 4 & 0,2 & 2 & 0,4 \\
\hline 4 & $\begin{array}{l}\text { Standart Mutu peyananan masing- masing bagian yang } \\
\text { tersambung dengan system berkala }\end{array}$ & 4 & 0,2 & 3 & 0,6 \\
\hline 5 & $\begin{array}{l}\text { Memiliki Tenaga medis dan non Medis Yang memiliki } \\
\text { STR dan cukup profesional. }\end{array}$ & 2 & 0,1 & 2 & 0,2 \\
\hline 6 & $\begin{array}{l}\text { Desain Bangunan RSIA akan berkonsep Smart Hospital } \\
\text { (seperti adanya : Minimarket, Restoran, dan Cafetaria) }\end{array}$ & 2 & 0,1 & 1 & 0,1 \\
\hline & Total & 14 & $\mathbf{0 , 9}$ & 15 & 2,4 \\
\hline
\end{tabular}


Tabel 2.

Internal Identifikasi Analisis Kelemahan (Weakness)

\begin{tabular}{clcccc}
\hline No & \multicolumn{1}{c}{ Identifikasi Kelemahan } & Nilai & Bobot & Rating & Skor \\
\hline 1 & $\begin{array}{l}\text { RSIA Samarinda Lokasinya kadang masih Rawan } \\
\text { Banjir }\end{array}$ & 2 & 0,2 & -3 & -0.6 \\
2 & $\begin{array}{l}\text { RSIA Samarinda memerlukan Izin baru } \\
\text { Belum ada Kebijakan untuk merekrut tenaga medis } \\
\text { Asing } \\
\text { Budaya Disiplin dan Etos Kerja Tenaga Medis yang } \\
\text { Masih Kurang }\end{array}$ & 4 & 0,1 & -1 & -0.4 \\
$\quad$ & Total & $\mathbf{1 2}$ & 0,1 & -2 & -0.6 \\
& & $\mathbf{0 , 5}$ & -2 & -0.6 \\
\hline
\end{tabular}

\section{Identifikasi Eksternal}

Identifikasi eksternal terdiri dari Peluang dan Ancaman yaitu Identifikasi yang berasal dari luar objek. Jika objeknya adalah sebuah organisasi Rumah Sakit, maka Identifikasi eksternalnya meliputi bagaimana dengan dukungan Pemerintah daerah, Dinas Kesehatan Kota dan Instansi-Instansi terkait lain.

Tabel 3.

Identifikasi Internal Factor Analisis Peluang (Opportunity)

\begin{tabular}{|c|c|c|c|c|c|}
\hline No & Identifikasi Peluang & Nilai & Bobot & Rating & Skor \\
\hline 1 & $\begin{array}{l}\text { Pelayanan masing-masing bagian di tawarkan } \\
\text { melebihi harapan pasien }\end{array}$ & 4 & 0.3 & 4 & 1.1 \\
\hline 2 & $\begin{array}{l}\text { Adanya Rujukan Berjenjang tentang pasien BPJS di } \\
\text { Faskes yang ada }\end{array}$ & 4 & 0.3 & 4 & 0.9 \\
\hline 3 & $\begin{array}{l}\text { Kebutuhan pelayanan medis yang beraneka ragam } \\
\text { jenisnya membuat RSIA semakin mampu untuk } \\
\text { meluaskan jaringannya. }\end{array}$ & 3 & 0.2 & 2 & 0.4 \\
\hline 4 & $\begin{array}{l}\text { PP Peralatan Medis Dan Non Medis yang lengkap dan } \\
\text { Pelayanan Terbaik membuat RSIA bisa jadi Rujukan }\end{array}$ & 2 & 0.1 & 2 & 0.3 \\
\hline 5 & $\begin{array}{l}\text { Ditunjuknya Kaltim Sebagai Ibukota Negara (IKN) } \\
\text { membuat peluang RSIA bersaing semakin besar. }\end{array}$ & 1 & 0.1 & 1 & 0.1 \\
\hline 6 & $\begin{array}{l}\text { Masih kurangnya Jumlah Tempat Tidur pasien dikota } \\
\text { Samarinda }\end{array}$ & 1 & 0,1 & 1 & 0,1 \\
\hline
\end{tabular}

$\begin{array}{lllll}\text { Total } & 14 & 1 & 14 & 2.9\end{array}$

Tabel 4.

Identifikasi Internal Factor Analisis Ancaman (Threat)

\begin{tabular}{clcccc}
\hline No & \multicolumn{1}{c}{ Identifikasi Strategi } & Nilai & Bobot & Ratin & Skor \\
\hline 1 & $\begin{array}{l}\text { Tarif harga kamar relatif mahal dari pesaing karena } \\
\text { menggunakan peralatan baru danh canggih }\end{array}$ & 1 & 3 & -0.3 & -0.9 \\
2 & $\begin{array}{l}\text { Layaanan Rujukan dari Rumah Sakit lain yang } \\
\text { beroperasi 24 jam menjadi kendala } \\
\text { Adanya rencana tawaran harga yang bermunculan } \\
\text { dari Rumah Sakit baru. }\end{array}$ & 2 & 3 & -0.1 & -0.6 \\
\hline
\end{tabular}


Berdasarkan hasil Identifikasi internal dan eksternal di atas, maka didapat hasilnya yaitu: Skor Kekuatan keseluruhan : 2.4, Skor keseluruhan Kelemahan : -2.2, Skor Peluang keseluruhan : 2.9, Skor Ancaman keseluruhan : -1.8.

Berdasarkan total skor yang ada, maka penentuan posisi dapat digambarkan dengan Matrik SWOT yang bisa dilihat pada Gambar di bawah. Untuk mendapatakan koordinatnya, dapat dicari dengan cara sebagai berikut: Hasil Koordinat Identifikasi Internal: (skor keseluruhan kekuatan - skor keseluruhan kelemahan) : $2=(2.4-(-2.2)): 2=2.3$, Hasil Koordinat Identifikasi Eksternal: (skor total peluang - skor total ancaman) $: 2=(2.9-(-1.8)): 2=2.35$ Jadi titik koordinatnya terletak pada $(2.3 ; \mathbf{2 . 3 5})$

Melihat hasil di atas, dapat dilihat posisi Rumah Sakit berada pada kuadran pertama, tetapi luas setiap kuadran perlu dihitung untuk meningkatkan analisis. Jumlah total dari tiap-tiap kuadran dapat digambarkan pada gambar satu ini :

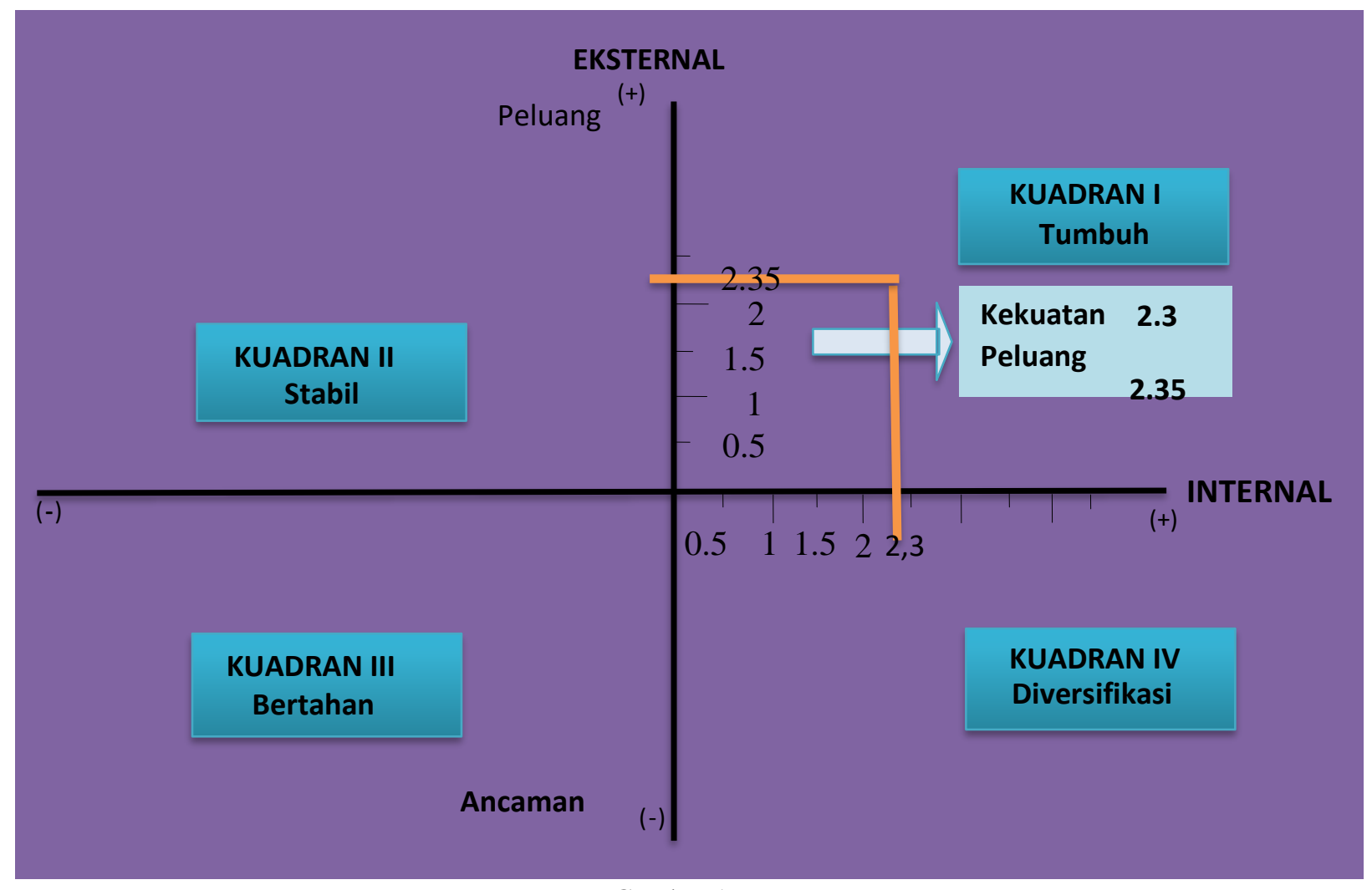

Gambar 1.

Matrix Swot Posisi Rumah Sakit

\section{HASIL DAN PEMBAHASAN}

Berdasarkan arah kebijakan RPJPD Kota Samarinda Tahun 2005-2025 tentang penguatan pembangunan Samarinda yang menyeluruh juga Rencana Stategis Badan Penelitian dan pengembangan daerah Kota Samarinda tahun 2016-2021. Terkait kelayakan pendirian RSIA Sempaja Kota Samarinda dengan ketentuan seperti yang terdapt dalam Pasal 7 ayat (1) bahwa rumah sakit harus memenuhi persyaratan terkait lokasi, bangunan, prasarana, sumber daya manusia, kefarmasian, peralatan, keselamatan lingkungan dan tata ruang serta Peraturan Menteri Kesehatan Nomor 3 tahun 2020 menggantikan Peraturan Menteri Kesehatan Nomor 30 Tahun 2019 sehubungan dengan klasifikasi dan otorisasi rumah sakit, jika izin operasi rumah sakit dikeluarkan oleh pihak terkait, maka sesuai fungsinya yakni rumah sakit sebagai 
institusi pelayanan kesehatan yang menyelenggarakan pelayanan kesehatan perorangan yang lengkap, baik pelayanan rawat inap, rawat jalan dan gawat darurat telah memiliki izin untuk didirikan. Pasal 1 ayat (4) izin pendirian rumah sakit yang selanjutnya disebut izin pemukiman adalah izin usaha yang diterbitkan oleh lembaga OSS untuk dan atas nama menteri, gubernur, atau bupati/wali kota setelah pemilik rumah sakit melakukan pendaftaran sampai sebelum pelaksanaan pelayanan kesehatan dengan memenuhi persyaratan dan/atau komitmen dan di Pasal 1 ayat (5) izin operasional rumah sakit yang selanjutnya disebut izin penyelenggaraan, dimana izin usaha atau penyelenggaraan yang diterbitkan oleh Lembaga OSS untuk dan atas nama menteri, gubernur, atau bupati/wali kota setelah pemilik rumah sakit memperoleh izin mendirikan. Hasil kajian berdasarkan penelitian yang dilakukan secara empiris dan normatif bahwa Pembangunan RSIA di Kota Samarinda layak untuk pendiriannya sesuai Permenkes Nomor 3 Tahun 2020 dalam Pasal 6 huruf b tentang Rumah Sakit Khusus dan Pasal 12 dan 13 ayat (1) huruf b tentang Rumah Sakit Khusus Ibu dan Anak. Adapun Dasar hukum yang mendukung berdirinya RSIA Kota Samarinda sebagai berikut:

1. Undang-Undang Nomor 36 Tahun 2009 tentang Kesehatan

2. Undang-Undang Nomor 44 Tahun 2009 tentang Rumah Sakit

3. Undang-Undang Nomor 23 Tahun 2014 tentang Pemerintahan Daerah

4. Undang-Undang Nomor 36 Tahun 2014 tentang Tenaga Kesehatan

5. Peraturan Pemerintah Nomor 47 Tahun 2016 tentang Fasilitas Pelayanan Kesehatan

6. Peraturan Pemerintah Nomor 24 Tahun 2018 tentang Pelayanan Perizinan Berusaha Terintegrasi Secara Elektronik

7. Peraturan Menteri Kesehatan Nomor 3 Tahun 2020 tentang Klasifikasi dan Perizinan Rumah Sakit.

8. Peraturan Daerah Kota Samarinda No.53 Tahun 2012, tentang tatacara pemungutan retribusi pelayanan kesehatan.

\section{KESIMPULAN}

1. RSIA bisa berusaha untuk menarik konsumen agar mereka meningkatkan kunjungan. Kunjungan bisa digambarkan sebagai fungsi dari frekuensi kunjungan dikalikan dengan jumlah kunjungan yang ada. Rumah sakit dapat mendorong konsumen untuk berkunjung lebih sering dan berkunjung lebih banyak dengan setiap kedatangan mereka ke rumah sakit. Promosi harga, iklan, publisitas, dan perluasan jaringan distribusi sangat mendukung kegiatan ini. Sebagai aturan, rumah sakit dapat mempertimbangkan cara untuk meningkatkan tingkat konsumsi yang ada yang mendasari tingkat belanja. Tingkat konsumsi adalah fungsi dari penggunaan layanan dikalikan dengan jumlah yang digunakan atau di konsumsi untuk setiap penggunaan.

2. Rumah Sakit bisa mengembangkan layanannya dengan lebih modern dan mempengaruhi konsumen yang bersaing. Peralatan yang dipakai harus lebih modern seperti identifikasi swot, Letak perbedaan adalah pada hal-hal atau target yang mau dicapai, atau pada kompetitor lainnya. Sedangkan pada nilai yang digunakan dipakai nilai pada pemakaian peralatan Rumah Sakit sendiri.

3. Rumah Sakit bisa mengembangkan bisnisnya dengan menggaet pelanggan dari luar yang bukan pengguna (non users) atau pelanggan potensial yang ada di lingkungan pasarnya. Sarana sebenarnya tidak ada perbedaan dengan yang dipakai pada Identifikasi internal. Perbedaannya ada di hal-hal atau tujuan yang ingin dicapai, yaitu para calon pelanggan luar dan yang bukan pengguna jasa layanan rumah sakit.

\section{UCAPAN TERIMAKASIH}

1. Kepala Balitbangda beserta team Balitbangda Kota Samarinda yang telah memfasilitasi kajian ini. 
2. Team Reviewer Jurnal Riset Inossa yang sudah memberikan masukan dan sarannya sehingga jurnal ini bisa diterbitkan.

3. Para Pihak yang tidak bisa kami sebutkan namanya yang telah mendukung sampai jurnal ini bisa di terbitkan.

\section{DAFTAR PUSTAKA}

Aarons, Gregory. A. (2006). Transformational and Transactional Leadership: Association With Attitudes Toward Evidence-Based Practice. Psychiatry Serve, 57(8), 1162-1169.

Antoncic, J.A., Antoncic, B. (2011). Employee Satisfaction Intrapreneurship and Firm Growth : A Model. Industrial Management And Data Systems, 111(4), 589 -607.

Asri, L. (2010). Budaya Organisasi. Yogyakarta: Graha Ilmu.

Bakhshi, A. Kumar., \& K., Rani, E. (2009). Organizational Justice Perceptions as Predictor of Job Satisfaction and Organization Commitment. International Journal Of Business And Management, 4(9), 145-154.

Bass, B.M. (2006). Leadership and performance beyond expectations. Free Press, New York, NY.

Bowling, N. A., \& Hammond, G. D. (2008). A Meta-Analytic Examination of The Construct Validity of The Michigan Organizational Assessment Questionnaire Job Satisfaction Subscale. Journal of Vocational Behavior, 73, 63 - 77.

Chang, C.S., \& Chang, H.C. (2010). Moderating Effect of Nurses' Customer-Oriented Perception Between Organizational Citizenship Behaviors and Satisfaction. Western Journal of Nursing Research, 32 (5), 628-643.

Cheung, M.F.Y., \& Wu, W-P. (2012). Leader-Member Exchange and Employee Work Outcomes In Chinese Firms: The Mediating Role Of Job Satisfaction. Asia Pacific Business Review, 18(1), 65-81.

Davis, F. W. (2011). Job Satisfaction and Stress.Journal of Physical Education, Recreation, and Andce. 52, 37-38.

Dessler, Gary. (2006). Manajemen Sumber Daya Manusia, Jilid Satu. Jakarta : PT. Indeks

Ghozali, Imam. (2008). Structural Equation Modeling : Metode Alternatif Dengan Partial Least Square. Semarang: Baand Penerbit Universitas Diponegoro.

Hardiansyah, (2011). Kualitas Pelayanan Publik. Yogyakarta: Penerbit Gava Media

Lembaran Negara Republik Indonesia. (2009). Nomor 144. Jakarta: Sekretariat Negara.

Lembaran Negara Republik Indonesia. (2009). Nomor 153. Jakarta : Sekretariat Negara.

Lembaran Negara Republik Indonesia. (2014) Nomor 298 . Jakarta : Sekretariat Negara.

Maier, C., Laumer, S., Eckhardt, A., \& Weitzel, T. (2012). Analyzing The Impact of HRIS Implementations on HR Personnel"s Job Satisfaction and Turnover Intention. Journal of Strategic Information Systems, XXX, 1 -15.

Memarzadeh, G., \& Mahmoudi, R.K. (2010). Applying Organizational Concepts in The Iran Public Sector: A Preliminary Empirical Work On Justice. European Journal Of Social Sciences, 14(4), 594-605.

Moorhead, G., \& Griffin, R.W. (2013). Perilaku Organisasi : Manajemen Sumber Daya Manusia and Organisasi, Edisi Sembilan. Jakarta : Penerbit Salemba Empat.

Nadiri, H., \& Tanova, C. (2010). An Investigation of The Role of Justice in Turnover Intentions, Job satisfaction and Organizational Citizenship Behavior In Hospitality Industry. International Journal of Hospitality Management, 29, 33-41.

Noe, R.A., Hollenbeck, J.R., Gerhart, 8., \& Wright, P.M. (2011). Manajemen Sumber Daya Manusia: Mencapai Keunggulan Bersaing, Edisi Enam. Penerbit : Salemba Empat.

Pemerintah Indonesia. (2009). Undang-Undang Nomor 36 tentang Kesehatan.

Pemerintah Indonesia. (2009). Undang-Undang Nomor 44 tentang Rumah Sakit.

Pemerintah Indonesia. (2014). Undang-Undang Nomor 36 tentang Tenaga

Kesehatan. 
Purbani, R.K., Jati, S.P., Sriatmi, A. (2013). Jurnal Kesehatan Masyarakat FKM Universitas Diponegoro Semarang, 2(2), $1-12$.

Siaila, S., Borolla, J., Wenno, M. (2019). Studi Kelayakan Pengembangan Rumah Sakit Sumber Hidup Gereja Protestan Maluku di Kota Ambon. Journal SOSOQ, 7(2), 70 - 85.

Tjiptono (1996). Manajemen Jasa, edisi. Yogyakarta: Andi.

Widodo. (2010). Model Pengembangan Kepuasan Kerja dengan Kepuasan Keluarga. Jurnal Bisnis Ekonomi Universitas Islam Sultan Agung, 61-73.

Yang, M-L. (2012). Transformational Leadership and Taiwanese Public Relations Practitioners Job Satisfaction and Organizational Commitment. Social Behavior and Personality, $40(1), 31-46$. 